\title{
European Partnership for Promoting Mental Health at School - Opportunity for Teachers Personal and Professional Development
}

\author{
Aurora Adina Colomeischi
}

\section{Introduction}

Considering the actual living environment on the global dimension as being extremely challenging, life giving to each person many occasions of confronting with difficulties but in the same time giving each one the opportunity to find solutions, to strive and to develop and flourish, the large community of thinkers and educational politicians bring out the idea of a specific education for the $21^{\text {st }}$ century. It is already known that the future is uncertain and it can't be predicted. The people need to be open mind and to be ready for it. But a question arises: How the new generation could be ready for a future which can't be predicted? In a position paper E2030 an international group of specialists try to offer an answer to these complexity of an unpredictable future (OECD, 2018): students will need to develop curiosity, imagination, resilience and self-regulation; they will need to respect and appreciate the ideas, perspectives and values of others; and they will need to cope with failure and rejection, and to move forward in the face of adversity; their motivation will be more than getting a good job and a high income; they will also need to care about the well-being of their friends and families, their communities and the planet. The Organization for Economic Co-operation and Development (OECD) has launched The Future of Education and Skills 2030 project (2018) which is trying to find answers at least for two main questions: 1) What knowledge, skills, attitudes and values will today's students need to thrive and shape their world? 2) How can instructional systems develop these knowledge, skills, attitudes and values effectively? Education 2030 shared vision states that in an era characterized by a new explosion of scientific knowledge and a growing array of complex societal problems, it is appropriate that curricula should continue to evolve, perhaps in radical ways.(OECD, 2018) The main goal of the future education is to help every learner to reach his/her full potential, to develop as a whole person and to build a future of well-being of individuals, communities and the large planet. We could notice this requirement and the 
future students to become more aware of their social responsibility not only for themselves and their small communities but also for the entire planet. It is needed of a concentered energy derived from all over the people to maintain the healthy planet and to face the dangers which are over the world.

\section{Education 2030 Project}

The premises of Education 2030 consist in some challenges detected as being prominent into nowadays world: environmental (such as global warming), economic (such as the consequences of the rapid growing of the scientific knowledge, financial interdependence, cyber-security, privacy protection) and social (continuous growing of population, migration, reshaping countries and communities, terrorism, wars). Now we could add to all these the pandemic situation confronting all over the world. Being aware of all these challenges it appears a need for broader education goals, focused on the individual and collective well-being, the concept being related more to the quality of life than to the wealth and access to the resources. This means «health, civic engagement, social connections, education, security, life satisfaction« (OECD, 2018, p.4) Education has a tremendous role in providing the development of the knowledge, skills, attitudes and values that enable people to become active, responsible and engaged citizens. In order to navigate through a complex and uncertain world, students need to be equipped with strong tools, and the representatives call it learner agency - agency which requires the ability to frame guiding purpose and identify actions to achieve a goal (OECD, 2018). A concept underlying the learning framework is «co-agency» - the interactive, mutually supportive relationships that enable learners to progress towards their goals. Co-agency is derived from the teachers' awareness upon the fact that the students need to be recognize as individualities but also they need to be acknowledged within their entire network of relationships. Agency could be developed at least through two ways: first is a personalized learning environment (each student would cultivate his/her own passion, will develop his/her own learning project, individually and in collaboration with others) and the second is building a solid foundation through literacy and numeracy, digital literacy, data literacy, physical health and mental wellbeing. The OECD presents a learning framework for the 2030 that shows how the future students will navigate their lives and the world: 
The OECD Learning Framework 2030
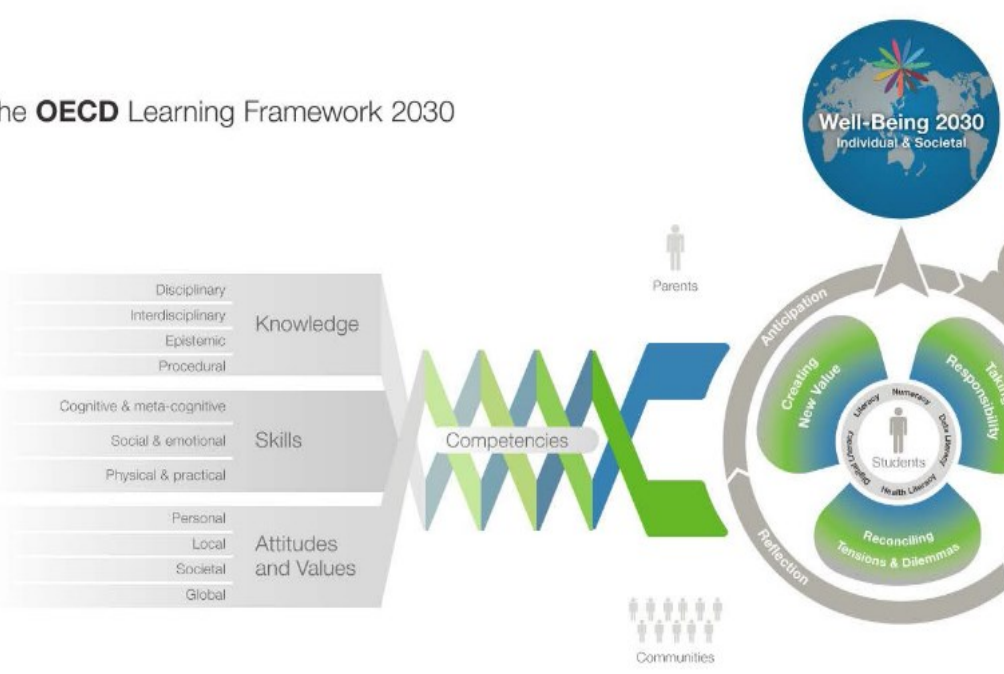

V14 OECD Learning Framework 2030

Fig. 1. The OECD Learning Framework 2030 (2018)

The OECD Education 2030 project (OECD, 2018, p.6) has identified three types of competencies, the transformative competencies, which are going to address the necessity for young people to be innovative, responsible and aware. These are to be:

mindedness

- Creating new values - adaptability, creativity, curiosity, open-

- Reconciling tensions and dilemmas - systems thinking, thinking and acting in a more integrated way

- Taking responsibility - acting ethically, self-regulation, self- control, self- efficacy, responsibility, problem-solving, adaptability.

All these complex competencies are going to be developed within a framework consisting in reflection, anticipation and action. Reflection is important to analyses things from different perspectives, anticipations mobilizes cognitive skills to foresee what would be needed in the future. After these process of reflection and anticipation, responsible action will contribute to the development the inter-related competencies necessary for engagement within the world.

\section{European Council Recommendation regarding the key competences for 2030}

The Recommendation (2018) suggest that the member states should support the development of key competences paying special attention to: 
raising the level of achievement of basic skills (literacy, numeracy and basic digital skills) and supporting the development of learning to learn competence as a constantly improved basis for learning and participation in society in a lifelong perspective; raising the level of personal, social and learning to learn competence to improve health conscious, future-oriented life management; fostering the acquisition of competences in sciences, technology, engineering and mathematics (STEM), taking into account their link to the arts, creativity and innovation and motivating more young people, especially girls and young women, to engage in STEM careers; increasing and improving the level of digital competences at all stages of education and training, across all segments of the population; nurturing entrepreneurship competence, creativity and the sense of initiative especially among young people, for example by promoting opportunities for young learners to undertake at least one practical entrepreneurial experience during their school education; increasing the level of language competences in both official and other languages and supporting learners to learn different languages relevant to their working and living situation and that may contribute to cross-border communication and mobility; fostering the development of citizenship competences with the aim of strengthening the awareness of common values, as referred to in Article 2 of the Treaty on European Union and the Charter of Fundamental Rights of the European Union; increasing the awareness of all learners and educational staff of the importance of the acquisition of key competences and their relation to society.

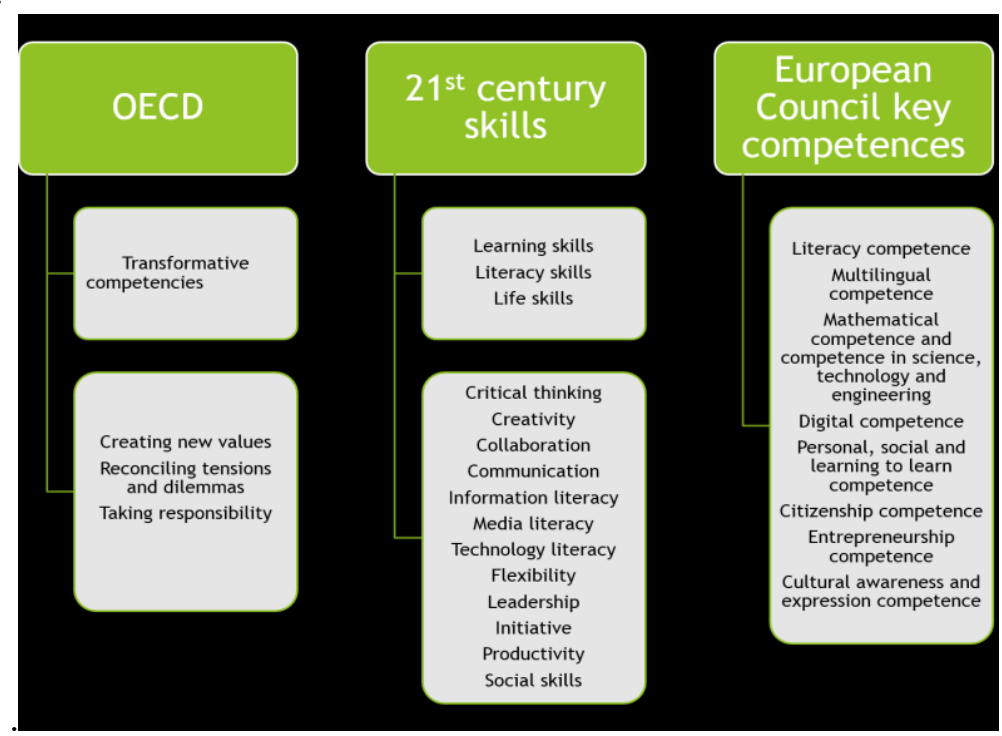

Fig. 2. Competences for the curriculum development 


\section{PROMEHS - A European Project - development of a curriculum to promote mental health at school}

European Union through its Educational Program ERASMUS+ offers the great opportunity to develop strategic partnerships in order to enhance, optimize or develop new educational policies and practices. In this section we intend to present a recent partnership experience which is in working progress and which is intending to promote a new educational policy to foster mental health promoting at school, beginning with the preschool education and continuing with primary and secondary school. The partnership is comprised by universities and local political agencies from 7 European countries and will develop a research based curriculum for mental health promotion.

This curriculum is based mainly on the key competence which refers to the personal, social and learning competence. This includes three specific aspects:

- Personal - self-awareness, physical and mental well -being

- Social - interpersonal, interaction and working with others

- Learning - lifelong learning strategies and career management skills

An overview of recent and on-going projects funded by the EU European Commission and academic literature reviews (Cefai et al., 2018) shows the interest and the need to integrate this set of competences and skills into the curricula of European education systems.

Development of social and emotional competences is indicated as one of the key aspects of inclusion in schools and school systems (Downs et al, 2017). The evidence furthermore shows that academic learning and social and emotional learning support one another. Social and emotional education enables students to regulate their emotions and deal with stress, cope with school requirements, solve problems more effectively, have healthier relationships, and work more collaboratively with others, providing thus a foundation for effective learning and academic success (Cefai \& Cavioni, 2014). A meta-analysis of over 200 studies (Durlak et al., 2011) reported that students who participated in social and emotional learning programs, scored significantly higher on standardized achievement tests when compared to peers who did not participate.

Taking into account these considerations the PROMEHS Project is focused to provide a social-emotional frame of learning, using experiential methodology to enable children to be more aware of their own personal life, to act more consciously, to interact in the most appropriate ways with their peers and adults, to cope with difficulties and to overcome the mental challenges. 
The EU Framework for Action on Mental Health and Well-being (2016) recognizes mental health promotion at school as one of the main priority of the public health agenda. Schools are an ideal setting in which to promote mental health for children and youth, providing an opportunity to reach large groups of children during their formative years of cognitive, emotional and behavioural development (Weare, 2000).

Although a number of initiatives aimed at reducing mental problems at school have been carried out in the last decade, a review of the current educational national policies in many EU countries reveals a lack of priority to wellbeing in schools as well as lack of comprehensive evidence-based programs to promote mental health in schools (Cefai et al., 2018; EC, 2016). Furthermore, mental health policies have not been assigned the same importance and priority across EU Countries.

Furthermore, a large number of scientific studies underlined that students learn more effectively, including their academic subjects, if they are happy in their work, if they are able to manage negative feelings and believe in themselves, when like their teachers, when they build positive relationship with peers and feel school is supporting and caring them (Weare, 2000).

In the school context, mental health promotion is more than the prevention of mental illness and it is not just only about preventing bullying, violence and at-risk behaviours, it also becomes about encouraging all who learn and work in schools to set and fully achieve their academic and life's goals, to love, to feel joyful, satisfied, full of life and to care about others.

Mental Health Promotion in schools is related to creating supportive and caring environments that promote and sustain positive mental health for everyone, both students and school staff.

The literature, in line with the WHO's framework for mental health (WHO, 2017), suggests a whole school approach to mental health promotion and prevention, including both curricular and systemic approaches, focusing on all children at universal level, including students, teachers, school leaders and parents, and addressing the issue specifically in the curriculum as well at classroom climate and whole school levels (Weare \& Nind, 2011; Cefai, Bartolo, Cavioni \& Downes, 2018).

The main aim of the PROMEHS project is to develop an evidencebased curriculum to promote positive mental health at school. The curriculum will seek to enhance the social and emotional well-being of students, improving their attitudes towards self, others, and learning, as well as reduce conduct problems and aggression, emotional distress and anxiety. The curriculum will be developed on the basis of existing knowledge on what has been found to work in mental health promotion in schools, both in 
terms of content as well mode of delivery and implementation (eg. Weare \& Nind, 2011, Durlak et al, 2011).

Teachers are now facing a range of new challenges to address students' emotional and social needs. PROMEHS will provide high-quality training for school staff as one of the most impacting and effecting factors in mental health promotion in school (Durlak, 2015).

PROMEHS will provide a systematic framework for the development and implementation of a universal curriculum, including a theoretical framework, activities for students, teachers and parents and guidelines for the school community and policy-makers. The findings and outcomes will then serve as the basis for national educational policies in the Member States in relation to mental health promotion in school. PROMEHS will be implemented in the six partner countries: Italy, Croatia, Greece, Latvia, Portugal, and Romania.

The theoretical framework underpinning the experimentation methodology is the evidence-based intervention approach. The effectiveness of PROMEHS over time will be demonstrated in rigorous scientific evaluations using the training study methodology.

\section{PROMEHS curriculum}

The curriculum will cover three main area of addressability: two of them represents the promoting mental health dimension, and the third is related to prevention dimension. The first two areas are described by the social - emotional learning approach, based on the CASEL SEL model, the second is related to resilience enhancing through school education. The third part of the curriculum is designed to meet the needs of prevention related to externalizing and internalizing mental health problems. 


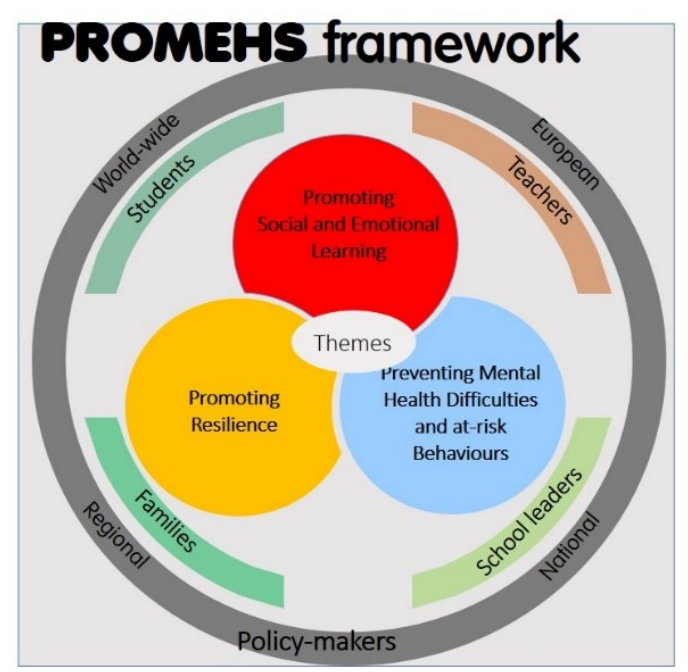

Fig. 3. Theoretical model of topics addressed by the PROMEHS curriculum (according to the Application Form, 2018)

The curriculum will be delivered by trained teachers and will include a series of activities to strengthen personal and interpersonal skills such as self-awareness, self-management, social awareness, relationship skills and responsible decision making, and to reduce behavioural problems and at-risk behaviours (fig. 3). These skills will serve as the building blocks of mental health and wellbeing in children and young people. The curriculum will be developmentally appropriate with different activities based on different ages and developmental stages of children and young people, including different sets of activities for kindergarten children, primary and secondary school students. It will also address the needs of children with individual educational needs and those from marginalized backgrounds, but presented within a universal framework for the whole class. The curriculum activities will also follow the «SAFE» procedure (CASEL, 2013) using a sequenced step-by-step training approach and active forms of learning focusing specific time and attention on skill development, and being explicit in defining those skills that need to be promoted. PROMEHS will help to foster safe and caring learning environments that build students' sense of belonging, connectedness and motivation to learn.

Social-emotional learning (SEL) represents one of the main targets for education of XXI century, being demonstrated that the non-cognitive skills, named also soft skills make a real difference related to performance in academic settings or at work, being valued for employment, cost effective from an economic point of view. As we could noticed within different 
competences frames, these non-cognitive skills appear to be some of the important skills the future generation needs in order to accomplish their potential and to adjust efficiently to the world. PROMEHS curriculum is centered on the model promoted by CASEL which figure out five main dimensions for SEL skills: self-awareness, self-management, social awareness, relationship skills, responsible decision-making. CASEL recent frame promotes the whole school approach and an integrated approach to SEL development, putting the five areas into contextual environments such as school, family, community at large. Self - awareness is described by the ability to recognize and understand one's own emotion, thoughts and values, to understand their influence on human results *such as performance, behavior). Based on this capacity one is confident and aware about his/her own strengths and limits, could develop as a congruent person, experiencing self-efficacy, having a growth mindset, developing interests and a sense of purpose.

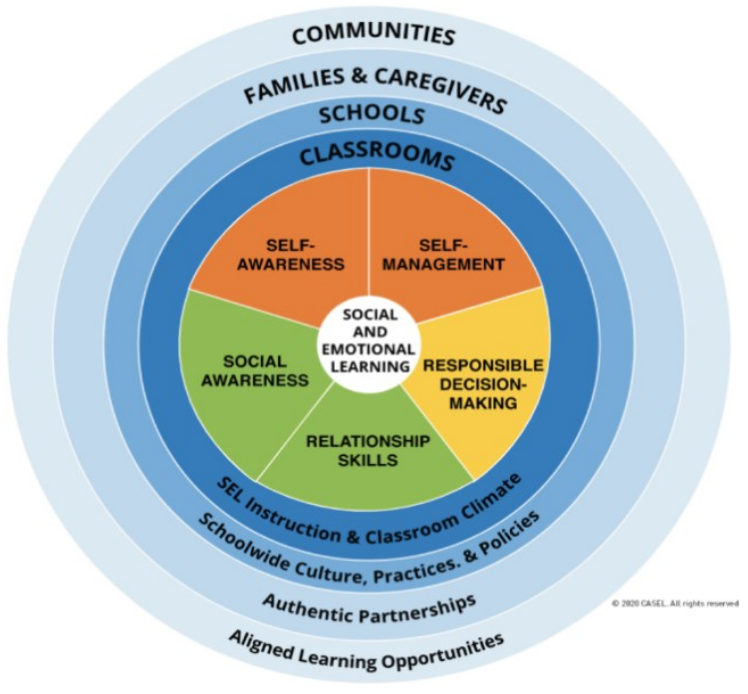

Fig. 4. 2020 CASEL's SEL framework (casel.org)

Self-management includes the abilities to manage emotions, thoughts and behavior effectively in order to achieve goals; this means the capacity to delay gratification, capacity to be tolerant at frustration, manage stress, selfmotivation, capacity for setting personal and collective goals, planning and organizational skills.

Social awareness includes the abilities to understand the perspective of others, to understand the feelings of others, including those belonging to different cultures. These abilities could be: compassion for others, 
recognizing social norms, showing gratitude and empathy, understanding the organizational influence on behavior.

Relationship skills includes the abilities to initiate and maintain healthy and supportive relationships. This means the capacity to communicate clearly, listen actively, cooperate, work collaboratively, provide leadership, seek or offer help.

Responsible decision - making includes the abilities to make constructive choices about personal and social behavior. This means to manifest curiosity and open-mindedness to identify solution for personal and social problems, to evaluate personal, interpersonal, community and institutional impacts, to evaluate the benefits and consequences of various actions for personal, social and collective wellbeing.

Resilience is conceptualized as the capacity to cope with the adversity in a healthy way, so the results resides not only in surviving but also in striving. Resilience means the capacity to bounce back after difficulties and to grow after encounter conflicts. Resilience could be enhanced through educational intervention, so that is why PROMEHS include into the curriculum for mental health promotion.

Preventing mental health difficulties and at risk behavior means that teachers will be informed about the possible risks to appear such as externalizing problems (violence and aggressive behavior) or internalizing problems (anxiety, depression), or addictive behaviors (substance abuse, technology addiction)

\section{Teachers professional and personal development - results of an exploratory study}

The present study intends to develop a general understanding upon the impact the mental health promotion program could have on the personal development of teachers. In a survey conducted in pandemic times (MayJune 2020) 955 teachers answer to multiple questionnaires investigating variables such as resilience, life satisfaction, mental health, wellbeing. We tried to find out the differences between teachers in terms of their previous professional training in counselling, emotional education or mental health, as well as their opinion related to using some emotional education elements within their pedagogical approach. 
Tab. 1. Differences in terms of previous training in counseling

\begin{tabular}{|c|c|c|c|c|c|}
\hline \multirow{2}{*}{ Resilience } & $\begin{array}{c}\text { Previous } \\
\text { training in } \\
\text { counseling }\end{array}$ & $\mathrm{N}$ & Mean & $\begin{array}{c}\text { Std. } \\
\text { Deviation }\end{array}$ & T test \\
\cline { 2 - 6 } & no & 648 & 40,1590 & 6,13282 & $\begin{array}{c}\mathrm{t}(953)=2.908, \mathrm{p}= \\
0.004\end{array}$ \\
\hline \multirow{3}{*}{ MentHealth } & yes & 646 & 64,2864 & 11,04592 & $\begin{array}{c}\mathrm{t}(951)=2.517, \mathrm{p}= \\
0.012\end{array}$ \\
\cline { 2 - 7 } & no & 307 & 62,2964 & 12,12166 & \\
\hline \multirow{3}{*}{ Wellbeing } & yes & 639 & 195,9562 & 25,84505 & $\mathbf{t}$ \\
\cline { 2 - 7 } & no & 303 & 188,6106 & 27,41223 & $\begin{array}{c}\mathrm{t}(940)=3.995, \\
\mathrm{p}=0.000\end{array}$ \\
\hline \multirow{2}{*}{ Burnout } & yes & 643 & 32,7387 & 13,86248 & $\mathrm{t}(946)=-3.324$, \\
\cline { 2 - 6 } & no & 305 & 36,0984 & 15,86467 & 0.001 \\
\hline
\end{tabular}

The sample consisted in 955 teachers, 787 females and 168 males, 499 from urban area, 456 from rural area in north east of Romania. The average age of the sample is 36 years old and the average experience in teaching is 12 years. The teachers practice their didactic activity at preschool level (226), primary education level (308), gymnasium level (257) and highschool level (149).

We have tested two hypothesis:

H1: There are differences in wellbeing, resilience, mental health and life satisfaction in terms of previous training in counselling / emotional education / mental health.

H2: There are differences in wellbeing, resilience, mental health and life satisfaction in terms of implementing of social emotional elements within pedagogical approach.

Results:

H1: In order to test the first hypothesis we used t-test for independent samples, having independent variable the previous training in counselling/ emotional education/ mental health and the dependent variables life satisfaction, resilience, mental health, wellbeing and burnout. 
Related to previous training in counselling, we found out significant differences for resilience, mental health, wellbeing and burnout of teachers, so that teachers who had a previous training in counselling show less burnout and a higher level of resilience, mental health and wellbeing than those who did not.

Tab. 2. Differences in terms of previous training in emotional education

\begin{tabular}{|c|c|c|c|c|c|}
\hline & $\begin{array}{c}\text { Previous training } \\
\text { in emotional } \\
\text { education }\end{array}$ & $\mathrm{N}$ & Mean & $\begin{array}{c}\text { Std. } \\
\text { Deviation }\end{array}$ & T test \\
\hline \multirow{2}{*}{ Life_satisfaction } & yes & 506 & 28,5277 & 4,43570 & \\
\cline { 2 - 6 } & no & 449 & 27,5323 & 4,56202 & $\begin{array}{c}\mathrm{t}(953)=3.415, \\
\mathrm{p}=0.001\end{array}$ \\
\hline
\end{tabular}

Teachers who had previous training in emotional education experience a higher level of life satisfaction compared with those who did not have a training in emotional education. Also, teachers who had a previous training related to mental health promotion show higher levels of life satisfaction and mental health in comparison with those who did not have such a training. 
Tab. 3. Differences in terms of SEL Implementation

$\begin{array}{cc}\text { SEL } & N \text { Mean Std. t test } \\ \text { imple } & \text { Devi } \\ \text { ment } & \text { ation }\end{array}$

Life Little 88 26,065,543

satisf or $\quad 82 \quad 55$

actio not

$\mathrm{n}$ at all

a lot $46128,584,272 \mathrm{t}(547$

$\begin{array}{lll}35 & 77 & \text { ) } \\ & = & -\end{array}$

$\mathrm{p}=0$.

000

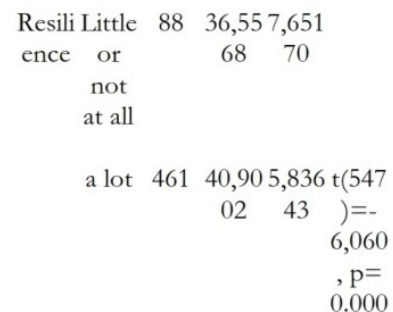

Well Little $85 \quad 179,926,13$ t(539 being or 059045$)=-$ not 5 , at all 779 , $\mathrm{p}=0$. 000

a lot $456 \quad 197,024,95$

$724 \quad 819$

Burn Little $86 \quad 41,0517,11$

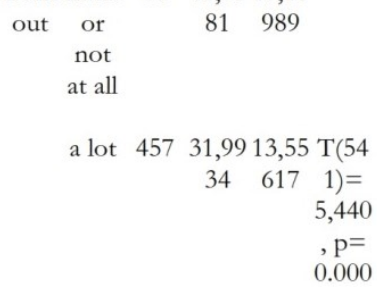


H2: (Table 3) We have tested the hypothesis regarding the differences between levels of life satisfaction, resilience, wellbeing, mental health and burnout in terms of the extent of implementation of emotional education elements within pedagogical approach. We have used t test, as independent variables we have used implementing emotional education elements with two dimensions: little or not at all implementation versus a high level of implementation. (We split the sample and considering only those who implement or not emotional education elements). Results show that there are differences of life satisfaction, resilience, wellbeing, mental health and burnout in terms of implementation extent of emotional education elements. Teachers who implement at a great extent the SEL elements are experiencing higher level of life satisfaction, resilience, wellbeing, mental health and lower level of burnout in comparison with teachers who implement at a very low extent SEL elements in their pedagogical approach.

The results showed that providing teacher training on subjects as emotional education or mental health promotion could contribute also to the enhancing of wellbeing of teachers. In the same time, teacher who are open to promote SEL elements in their pedagogical approach are prone to experience better levels of wellbeing, life satisfaction, resilience and mental health and lower level of burnout.

\section{Conclusions}

These results give us confidence that the PROMEHS project will contribute to the enhancing the quality of life of teachers so they could be more engaged in their didactic mission. The project intends to develop an educational policy in order to be implemented through the schools within partnership countries and beyond. Guidelines and recommendation for policy makers and stakeholders on mental health promotions in schools will be delivered. The intervention for teachers training in the area of counseling and mental health promotion could also contribute to the enhancing the resilience and wellbeing of teachers so they will be better agents in pursuing educational aims.

\section{References}

Ananiadou, K., \& Claro, M. (2009). 21st Century Skills and Competences for New Millennium Learners in OECD Countries. OECD Education Working Papers, No. 41. Paris: OECD Publishing

COUNCIL RECOMMENDATION on key competences for lifelong learning. (2018). Official Journal of the European Union https://eur-lex.europa.eu/legal- 
Trends and Prospects of the Education System and Educators' Professional ...

content/EN/TXT/?uri=uriserv\%3AOJ.C .2018.189.01.0001.01.ENG\&toc $\equiv \mathrm{OJ} \% 3 \mathrm{AC} \% 3 \mathrm{~A} 2018 \% 3 \mathrm{~A} 189 \% 3 \mathrm{ATOC}$

CASEL - Collaborative for Academic, Social, and Emotional Learning. (2013).

CASEL Guide: Effective Social and Emotional Learning Programs Preschool and Elementary School Edition. http://www.casel.org/preschooland-elementary-edition-casel-guide/

Cefai C., Bartolo P. A., Cavioni V., Downes, P. (2017). Integrating Social and Emotional Education (SEE) in the School Curriculum across the EU, NESET II report, Luxembourg: Publications Office of the European Union

Cefai, C.; Cavioni, V. (2014). Social and emotional education in primary school: integrating theory and research into practice. NY, USA: Springer

Dovidio, J. F., Isen, A. M., Guerra, P., Gaertner, S. L., \& Rust, M. (1998). Positive affect, cognition, and the reduction of intergroup bias. In C. Sedikides, J. Schopler, \& C. A. Insko (Eds.), Intergroup cognition and intergroup behavior (pp. 337-366). Mahwah, NJ, US: Lawrence Erlbaum Associates Publishers.

Downes, P., Nairz-Wirth, E., Rusinaite, V. (2017). Structural Indicators for Inclusive Systems in and around Schools, NESET II report, Luxembourg: Publications Office of the European Union,

Durlak, J. A., Weissberg, R. P., Dymnicki, A. B., Taylor, R. D. (2011). The impact of enhancing students' social and emotional learning: A meta-analysis of school-based universal interventions. Child Development, 82 (1), 474-501

Durlak, J. A., Domitrovich, C. E., Weissberg, R. P., \& Gullotta, T. P. (Eds.). (2015). Handbook of social and emotional learning: Research and practice. New York, NY, US: The Guilford Press.

Frankl, V. (1985). Man's Search for Meaning. Pocket Books

Fredrickson, B. L. (2001). The role of positive emotions in positive psychology: The broaden-and-build theory of positive emotions. American Psychologist, $56,218-226$

Fredrickson, B. L. (2000). Cultivating positive emotions to optimize health and well-being. Target article in Prevention and Treatment, 3

Hirsh, \& Anderson, (2007). Positive affect increases the breadth of attention selection, Proceedings of the National Academy of Sciences, 104(1), 383-8

Johnson, K. \& Fredrickson, B. (2005). We All Look the Same to Me: Positive Emotions Eliminate the Own-Race Bias in Face Recognition, Psychological Science, 16(11), 875-81.

OECD. (2018). The Future of Education and Skills. Education 2030. The Education We Want.

https://www.oecd.org/education/2030/E2030\%20Position \%20Paper $\% 20$ ( 05.04.2018).pdf

PROMEHS. Promoting Mental Health at School. https://www.promehs.org/ 
ISE . (2016). Repere pentru proiectarea si actualizarea Curriculumului National. Document de Politici Educationale. Institutul de Stiinte ale Educatiei (Sciences of Education Institute) http://www.ise.ro/repere-pentru-proiectarea-si-actualizareacurriculumului-national/

Schmitz, De Rosa, \& Anderson. (2009). Opposing Influences of Affective State Valence on Visual Cortical Encoding, The Journal of Neuroscience: The Official Journal of the Society for Neuroscience, 29(22), 7199-207

Seligman, M. (2012) Flourish: A Visionary New Understanding of Happiness and Wellbeing. Free Press

Steger, M. F., Frazier, P., Oishi, S. \& Kaler,M. (2006). The Meaning in Life Questionnaire: Assessing the Presence of and Search for Meaning in Life. Journal of Counseling Psychology, 53 (1), 80-93.

The Future of Education and Skills. Education 2030. The Education We Want. (2018). OECD https://www.oecd.org/education/2030/E2030\%20Position $\% 20 \operatorname{Paper}^{2} \% 20$ ( 05.04.2018).pdf

Weare, K. (2000). Promoting Mental, Emotional and Social Health: A Whole School Approach. London, Routledge

Weare, K., \& Nind, M. (2011). Mental Health Promotion and Problem Prevention in Schools: What Does the Evidence Say? Health Promotion International, 26, i29-i69 www.casel.org 